\title{
Influence of Stratospheric Sudden Warming on AIRS Midtropospheric $\mathrm{CO}_{2}$
}

\author{
XUN JIANG AND JINGQIAN WANG \\ Department of Earth and Atmospheric Sciences, University of Houston, Houston, Texas \\ Edward T. Olsen, Thomas Pagano, and Luke L. Chen \\ Science Division, Jet Propulsion Laboratory, California Institute of Technology, Pasadena, California \\ YUK L. YUNG \\ Division of Geological and Planetary Sciences, California Institute of Technology, Pasadena, California
}

(Manuscript received and in final form 15 February 2013)

\begin{abstract}
Midtropospheric $\mathrm{CO}_{2}$ retrievals from the Atmospheric Infrared Sounder (AIRS) were used to explore the influence of stratospheric sudden warming (SSW) on $\mathrm{CO}_{2}$ in the middle to upper troposphere. To choose the SSW events that had strong coupling between the stratosphere and troposphere, the authors applied a principal component analysis to the NCEP/Department of Energy Global Reanalysis 2 (NCEP-2) geopotential height data at 17 pressure levels. Two events (April 2003 and March 2005) that have strong couplings between the stratosphere and troposphere were chosen to investigate the influence of SSW on AIRS midtropospheric $\mathrm{CO}_{2}$. The authors investigated the temporal and spatial variations of AIRS midtropospheric $\mathrm{CO}_{2}$ before and after the SSW events and found that the midtropospheric $\mathrm{CO}_{2}$ concentrations increased by 2-3 ppm within a few days after the SSW events. These results can be used to better understand how the chemical tracers respond to the large-scale dynamics in the high latitudes.
\end{abstract}

\section{Introduction}

In addition to the trend (Keeling et al. 1995) and the annual cycle (Pearman and Hyson 1980, 1981; Cleveland et al. 1983; Bacastow et al. 1985; Keeling et al. 1996), the atmospheric $\mathrm{CO}_{2}$ also exhibits variability at different time scales (Bacastow 1976; Enting 1987; Feely et al. 1987; Keeling and Revelle 1985; Keeling et al. 1995; Dargaville et al. 2000; Dettinger and Ghil 1998; KeppelAleks et al. 2011). Some recent studies further suggest that atmospheric processes have significant influences on the temporal variability of $\mathrm{CO}_{2}$ ( $\mathrm{Li}$ et al. 2010; Jiang et al. 2010; Wang et al. 2011; Jiang et al. 2013, 2012). It was found that the intraseasonal variability (e.g., MaddenJulian oscillation and semiannual oscillation) influence $\mathrm{CO}_{2}$ concentrations in the middle troposphere ( $\mathrm{Li}$ et al. 2010; Jiang et al. 2013). Interannual variability (e.g., El

\footnotetext{
Corresponding author address: Xun Jiang, Department of Earth and Atmospheric Sciences, University of Houston, 4800 Calhoun Rd., Houston, TX 77004.

E-mail: xjiang7@uh.edu
}

Niño-Southern Oscillation) can also modulate $\mathrm{CO}_{2}$ concentrations at the surface and midtroposphere (Keeling et al. 1995; Jones et al. 2001; Nevison et al. 2008; Jiang et al. 2010; Jiang et al. 2012).

The above investigations mainly focus on exploring the $\mathrm{CO}_{2}$ variability at the surface or are limited in the tropical to midlatitude regions. Compared with numerous studies of the $\mathrm{CO}_{2}$ variability in the low and middle latitudes, there are relatively few studies of the $\mathrm{CO}_{2}$ variability in the high latitudes, mainly because of the limited observations. The global distributions of chemical species retrieved from the Atmospheric Infrared Sounder (AIRS) offer a unique opportunity to study the influence of the large-scale dynamics on the $\mathrm{CO}_{2}$ in the polar region. In this paper, AIRS midtropospheric $\mathrm{CO}_{2}$ data were used to understand the coupling between the stratosphere and the troposphere. Specifically, we studied the response of $\mathrm{CO}_{2}$ to the stratospheric sudden warming ( $\mathrm{SSW}$ ), which is an example of strong stratosphere-troposphere coupling.

Stratospheric warming is an important phenomenon in the winter months in the stratosphere (Quiroz 1975; 
(a)

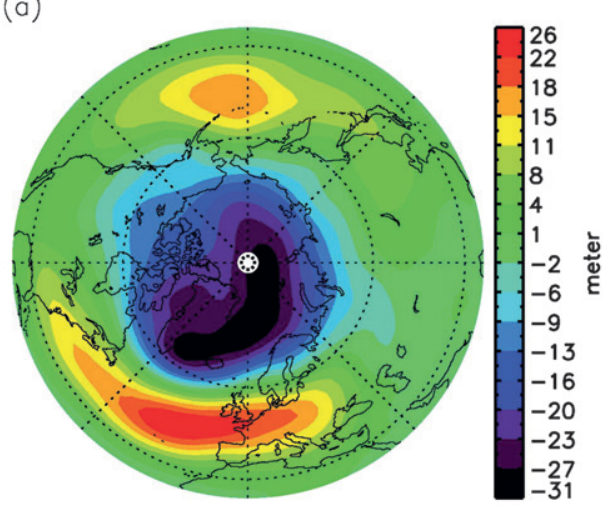

(c)

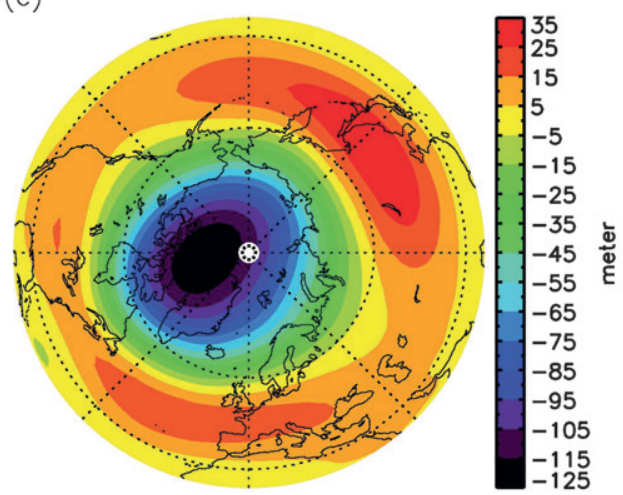

(b)

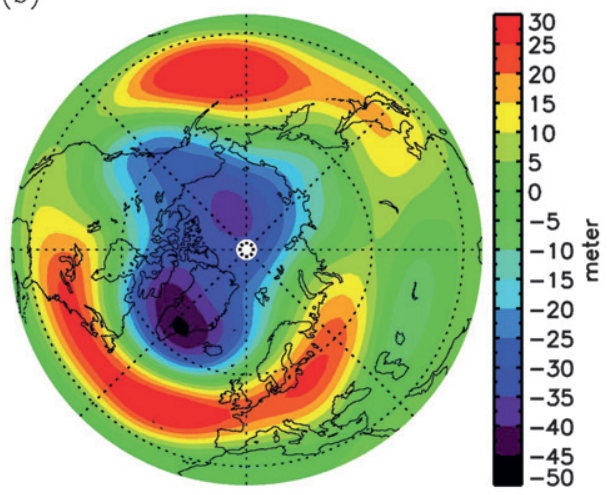

(d)

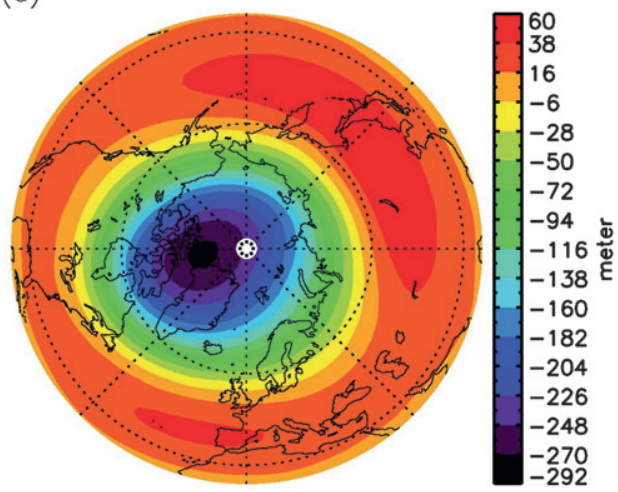

FIG. 1. Spatial pattern of NCEP-2 geopotential height's leading mode at (a) 850, (b) 500, (c) 100, and (d) $30 \mathrm{hPa}$.

Quiroz et al. 1975; Labitzke 1977; Kodera et al. 2000; Limpasuvan et al. 2004; Charlton and Polvani 2007; Charlton et al. 2007; Yoshida and Yamazaki 2011; Kuttippurath and Nikulin 2012; Garfinkel et al. 2012). Labitzke and Naujokat (2000) have classified the stratospheric warmings into four types. These include major midwinter warming in January-February, minor warming, Canadian warming, and final warming. During the stratospheric warming, the temperature increases and circumpolar winds reverse direction. Stratospheric warming starts from the upper stratosphere. Some stratospheric warmings can penetrate into the middle stratosphere and culminate in a major warming (Quiroz 1975; Quiroz et al. 1975). Other stratospheric warmings are restricted to the upper stratosphere, so their influence on the entire stratosphere is limited. The latter are also referred to as minor warmings. Stratospheric warmings also display interannual variability, which has been studied by Labitzke (1977). Limpasuvan et al. (2004) examined the composite of 39 major and minor warming events using National Centers for Climate Prediction-National Center for Atmospheric Research (NCEP-NCAR) reanalysis data and found that the forcing by planetary waves leads to the weakening of the stratospheric polar vortex and downward propagation of the positive temperature anomalies during the stratospheric warming growth phase. On the other hand, the vertical velocity in the residual circulation decreases in the polar region during the stratospheric warming decay phase (Limpasuvan et al. 2004). Using both NCEP-NCAR and 40-yr European Centre for Medium-Range Weather Forecasts (ECMWF) Re-Analysis (ERA-40) datasets, Charlton and Polvani (2007) constructed a comprehensive climatology for the major midwinter warming events. They classified stratospheric warmings into events with and without the splitting of the stratospheric polar vortex. These two types of events are found to be dynamically distinct. The influence of vortex splitting events on the midstratospheric temperature lasts longer than the vortex displacement events. Manney et al. (2005) studied the stratospheric warmings in the Arctic winter and found that there are unusually warm winters in the past six Arctic winters (1999-2004) compared with all events since 1990s. The SSW can also influence the concentrations of tracers (e.g., $\mathrm{O}_{3}, \mathrm{CO}$, and $\mathrm{H}_{2} \mathrm{O}$ ) (Manney et al. 2009; De Wachter et al. 2011; Sofieva et al. 2012). 

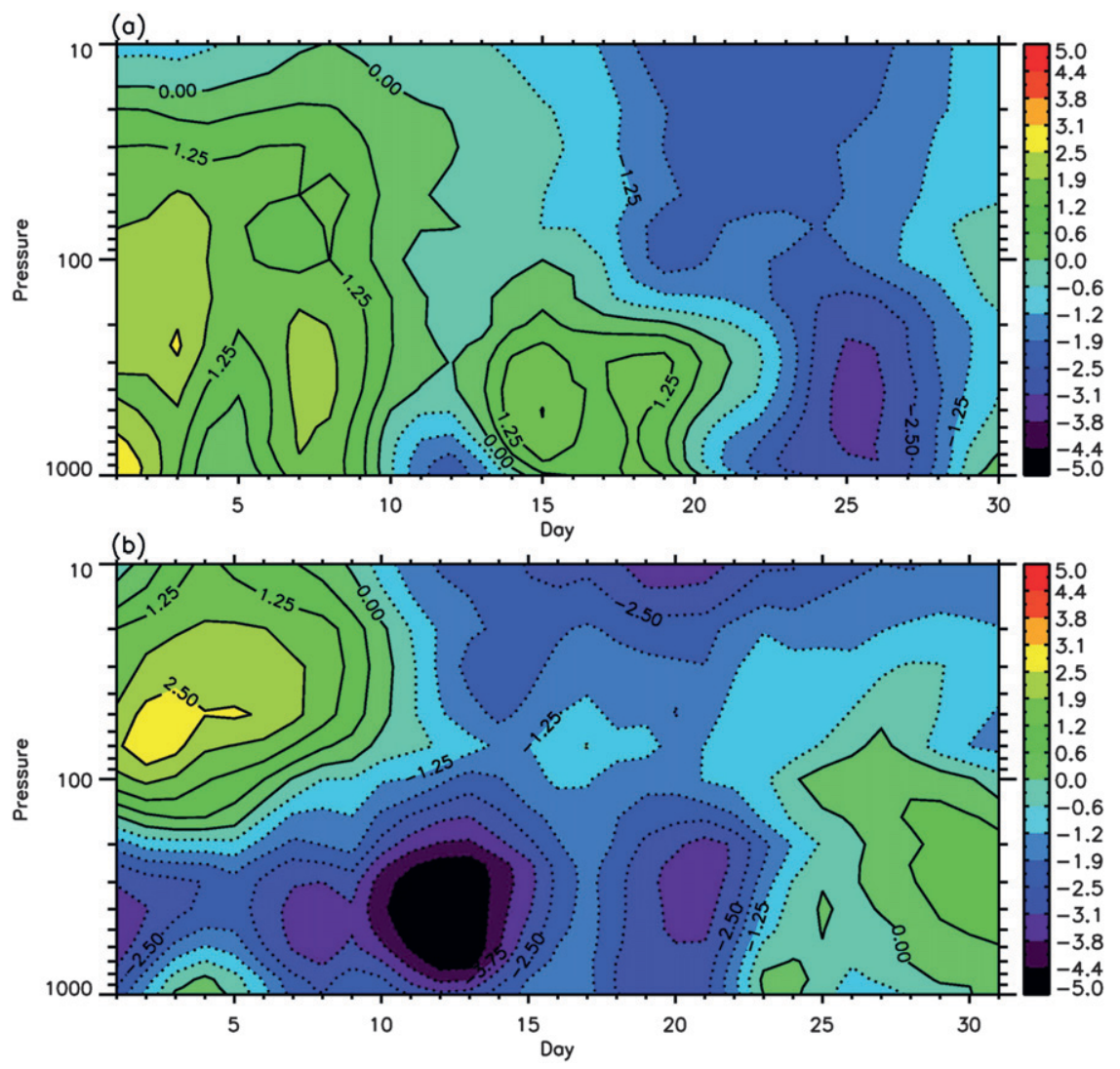

FIG. 2. Vertical structure of northern annular mode index derived from NCEP-2 geopotential height spanning (a) 1-30 Apr 2003 and (b) 1-31 Mar 2005.

In this paper, we focused on two SSW events (a final warming event in April 2003 and an SSW event in March 2005). Events in April 2003 and March 2005 were chosen, for both cases represent a strong and clear coupling between the stratosphere and troposphere. We investigated the influence of two stratospheric warming events on a midtropospheric tracer, $\mathrm{CO}_{2}$, which are retrieved from the AIRS on board the National Aeronautics and Space Administration (NASA) Earth Observing System (EOS)-Aqua satellite.

\section{Data}

AIRS version 5 midtropospheric $\mathrm{CO}_{2}$ data were used in this work. AIRS is a cross-track scanning grating spectrometer with 2378 channels from 3.7 to $15.4 \mu \mathrm{m}$ with a $13.5-\mathrm{km}$ field of view in the nadir (Aumann et al. 2003). AIRS data include $\mathrm{O}_{3}, \mathrm{CO}_{2}, \mathrm{CO}, \mathrm{CH}_{4}, \mathrm{H}_{2} \mathrm{O}$, temperature, and cloud distribution (Chahine et al. 2006). Since its launch in May 2002, AIRS has demonstrated a stability of better than $16 \mathrm{mK} \mathrm{yr}^{-1}$ with a spectral accuracy of the center frequency of $2 \mathrm{ppm}$ (Aumann et al.
2004, 2006). The AIRS retrieval algorithm incorporates information from a companion microwave sounder, the Advanced Microwave Sounding Unit (AMSU), to retrieve in the presence of clouds on a horizontal scale of 1 AMSU field of view or $45 \times 45 \mathrm{~km}^{2}$ in the nadir-the equivalent of $3 \times 3$ AIRS footprints (Susskind et al. 2003).

The mixing ratios of $\mathrm{CO}_{2}$ were retrieved from the radiance data in the spectral range $690-725 \mathrm{~cm}^{-1}$ by the vanish partial derivative (VPD) method (Chahine et al. 2005, 2008; Olsen 2011). AIRS midtropospheric $\mathrm{CO}_{2}$ retrievals are available over land and ocean and under clear and cloudy conditions. AIRS midtropospheric $\mathrm{CO}_{2}$ retrievals are available at $2^{\circ}$ (latitude) $\times$ $2.5^{\circ}$ (longitude) at $90^{\circ} \mathrm{S}-90^{\circ} \mathrm{N}$ from September 2002 to the present. The maximum sensitivity of AIRS midtropospheric $\mathrm{CO}_{2}$ retrieval is from 500 to $300 \mathrm{hPa}$. The midtropospheric $\mathrm{CO}_{2}$ retrieved via the VPD method captures the correct $\mathrm{CO}_{2}$ seasonal cycle and trend, and agrees well with the aircraft $\mathrm{CO}_{2}$ from Comprehensive Observation Network for Trace Gases by Airliner (CONTRAIL; Chahine et al. 2005), Intercontinental Chemical Transport 

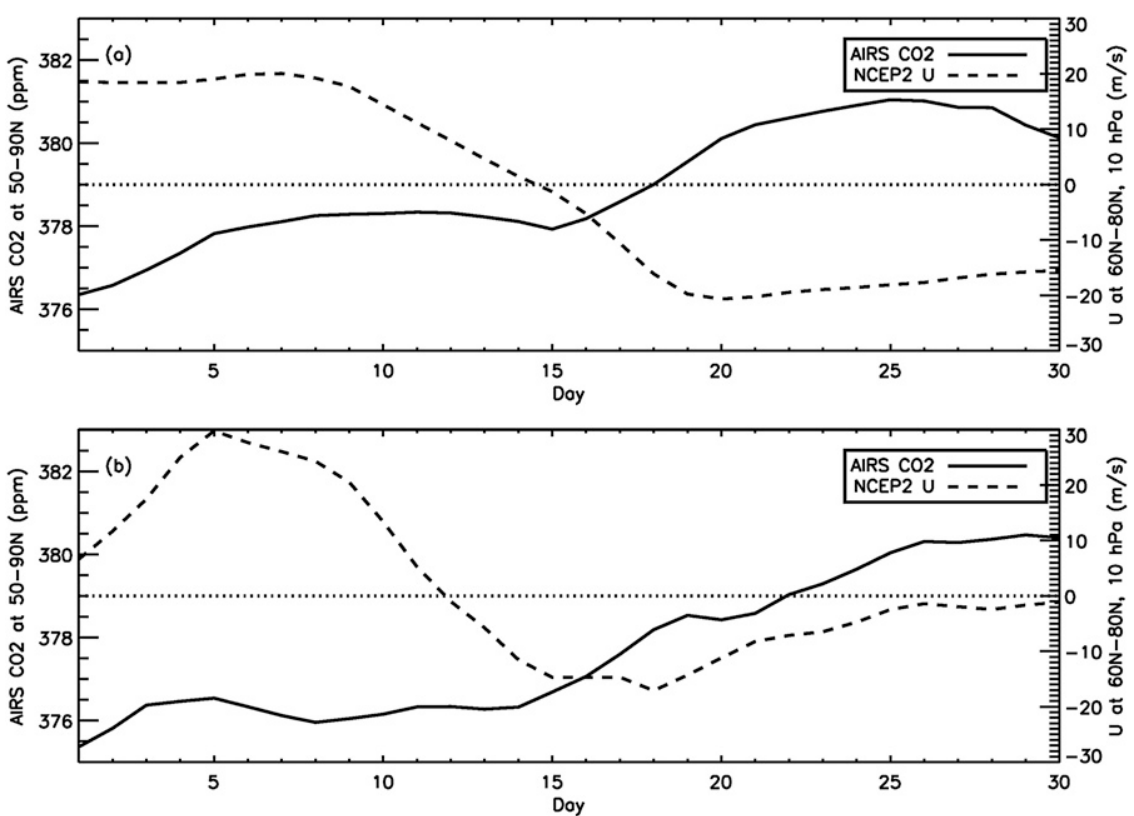

FIG. 3. Time series of 5-day-running-mean AIRS midtropospheric $\mathrm{CO}_{2}$ averaged over $50^{\circ}-$ $90^{\circ} \mathrm{N}$ (solid line) and 10 -hPa NCEP-2 zonal wind averaged over $60^{\circ}-80^{\circ} \mathrm{N}$ (dashed line) during (a) 1-30 Apr 2003 and (b) 1-31 Mar 2005.

Experiment-North America (INTEX-NA), and Spurengastransport in der Tropopausenregion (SPURT; Olsen et al. 2008). The precision of the AIRS-retrieved $\mathrm{CO}_{2}$ is within 1-2 ppmv ( 0.5\%) (Chahine et al. 2008; Olsen et al. 2008).

\section{Results}

Stratospheric warmings have important influence on the exchange between the stratosphere and troposphere. During the stratospheric warming events, polar stratospheric temperature rise and circumpolar flow reverse direction in a few days. After the SSW events, the vortex strength decreases, with a shrinking spatial coverage. Therefore, a critical point in our discussion is to track the vortex strength during the SSW events. To represent the vortex strength, we calculated the first principal component (PC1) of the daily time series from the NCEP/ Department of Energy Global Reanalysis 2 (NCEP-2) geopotential height (GPH). First, we applied the principal component analysis (PCA) method (Richman 1986; Preisendorfer 1988; Thompson and Wallace 2000; Jiang et al. 2008a,b) to the deseasonalized and latitudinally weighted monthly mean GPH from $20^{\circ}$ to $90^{\circ} \mathrm{N}$ from 2000 to 2009. Seasonal cycles for each time series were removed; cycles were determined by taking averages for each month independently. The details for the PCA decomposition of the scaled, deseasonalized GPH anomaly $\Omega_{A}$ can be represented as

$$
\Omega_{A}(t, \theta, \varphi)=\sum p_{i}(t) e_{i}(\theta, \varphi),
$$

where $t$ is time, $\theta$ is longitude, $\varphi$ is longitude, $p_{i}$ is the $i$ th $\mathrm{PC}, e_{i}$ is the $i$ th $\mathrm{EOF}$, and the summation is over all of the eigenfunctions with eigenvalues arranged in descending order. To recover the spatial patterns for the original (unscaled) GPH anomaly, we performed a multiple linear regression for each grid point $(\theta, \varphi)$, using as predictors the PC time series $p_{i}(t)$. The resulting linear regression coefficients $C_{i}(\theta, \varphi)$ are the spatial patterns of the GPH variability associated with the $i$ th PC time series $p_{i}(t)$. Finally, we regressed the first four dominant spatial patterns on the daily GPH to obtain the daily PC time series.

We applied the same method for the GPH data at 17 pressure levels from 1000 to $10 \mathrm{hPa}$. The spatial patterns for the first modes at $850,500,100$, and $30 \mathrm{hPa}$ are shown in Figs. 1a-d. The first modes at 850, 500, 100, and $30 \mathrm{hPa}$ capture $17.4 \%, 15.7 \%, 35.2 \%$, and $54.3 \%$ of the total variance, respectively. The first leading mode captures less variability in the troposphere than that in the stratosphere, for there is more variability in the other modes in the troposphere. The values for the first modes are negative (positive) in the polar region (low latitudes), which represents the positive phase of the northern annular modes. These results are similar to those in Thompson and Wallace (2000) and Baldwin and Dunkerton (2001). We explored the daily PC1 time series for the first mode 
(a)

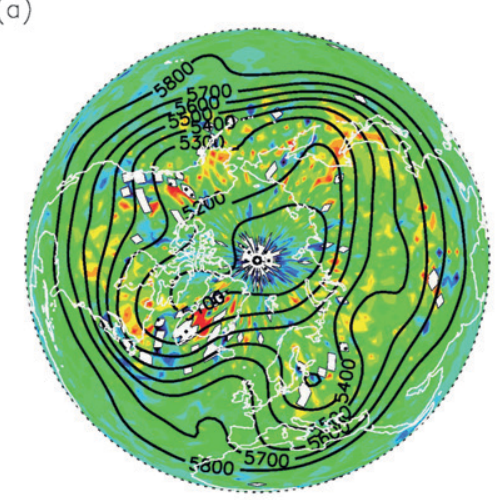

(c)

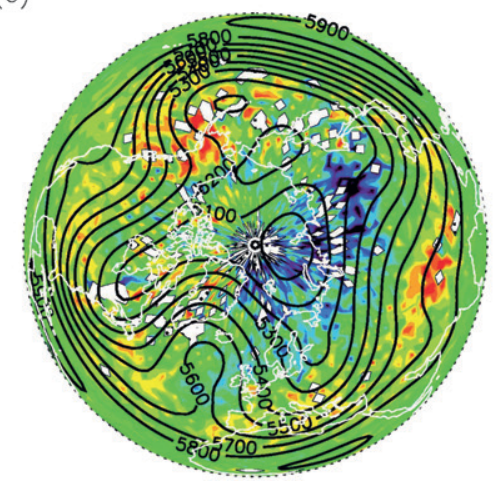

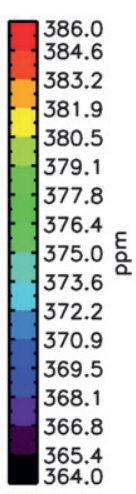

(b)

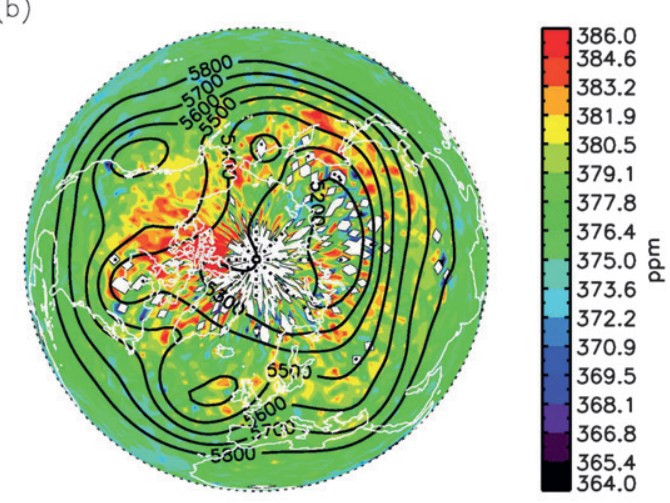

(d)

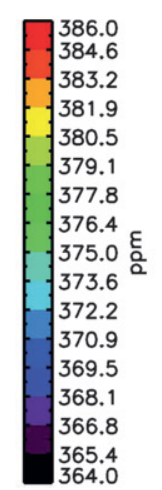

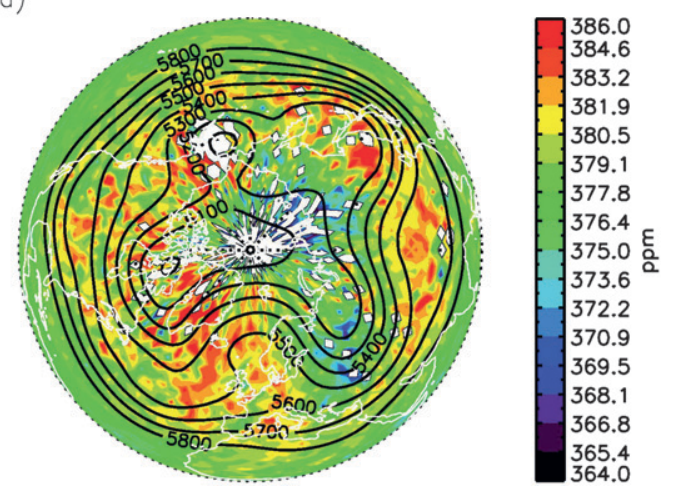

FIG. 4. Stereographic maps of AIRS $\mathrm{CO}_{2}$ during (a) 1-10 Apr 2003, (b) 21-30 Apr 2003, (c) 1-10 Mar 2005, and (d) 22-31 Mar 2005.

at 17 pressure levels in all winters from 2003 to 2009. Two cases, which represent strong and clear coupling between the stratosphere and troposphere, were chosen to investigate the influence of SSWs on the midtropospheric AIRS $\mathrm{CO}_{2}$ in the polar region. Some SSWs (e.g., January 2009 and February 2008) were not chosen in this paper because they did not propagate down to the midtroposphere. In the future, we will investigate the influence of all SSWs on the AIRS stratospheric $\mathrm{CO}_{2}$ (Olsen et al. 2011) when the stratospheric $\mathrm{CO}_{2}$ retrievals become publicly available.

The daily PC1 for the first mode is plotted as a function of pressure for the two cases (1-31 April 2003 and 131 March 2005) in Fig. 2. Positive value for PC1 represents a strong polar vortex, while negative value for PC1 represents a weak polar vortex. PC1 switched sign around 15 April 2003 and 11 March 2005 in the upper stratosphere as shown in Figs. 2a and 2b, respectively. The strength of the polar vortex decreased after 15 April 2003 and 11 March 2005, which were the times when the final warming and SSW events happened. In April 2003, the polar vortex dissipated after the stratospheric warming event. So the case in April 2003 is a final warming event. In March 2005, the polar vortex's strength was restored after this SSW event and was finally destroyed in April 2005. Thus, the case in March 2005 is classified as a major SSW event. After the final warming and SSW events, the strength of the polar vortex decreased and there was less mixing between the stratosphere and troposphere in the polar region.

To reveal the temporal variation of the AIRS midtropospheric $\mathrm{CO}_{2}$ during the final warming and SSW events, we calculated the 5-day-running-mean polar AIRS midtropospheric $\mathrm{CO}_{2}$ during April 2003 and March 2005 in Fig. 3. The 5-day-running-mean AIRS midtropospheric $\mathrm{CO}_{2}$ was calculated to ensure a good spatial coverage of the data over the polar region. NCEP-2 $10-\mathrm{hPa}$ zonal winds averaged over $60^{\circ}-80^{\circ} \mathrm{N}-\mathrm{a}$ WMO method used to identify the SSW-were calculated over the same time periods so we could better track the SSW events. Polar 10-hPa zonal winds changed direction from westerly to easterly on 15 April 2003 and 12 March 2005, which represented the time for the SSW events. After the SSW events, the polar $\mathrm{CO}_{2}$ concentrations increased by $2-3$ ppm within a few days as shown by the blue lines in Fig. 3. The changes in the AIRS midtropospheric $\mathrm{CO}_{2}$ before the SSWs (e.g., 10-15 April 2003; 5-10 March 2005) are within $0.5 \mathrm{ppm}$, which is smaller than the 
2-3-ppm change seen after the SSWs. It suggests that the 2-3-ppm increase of $\mathrm{CO}_{2}$ during the SSW is significant.

Spatial distributions for the AIRS midtropospheric $\mathrm{CO}_{2}$ mixing ratio before and after SSWs are shown in Fig. 4. Figures $4 \mathrm{a}$ and $4 \mathrm{c}$ are the 10-day mean of AIRS midtropospheric $\mathrm{CO}_{2}$ concentrations and the NCEP-2 GPH before the final warming and the SSW. The GPH decreased with the latitude and there was less $\mathrm{CO}_{2}$ at the polar region before the SSW. After the SSW, the polar vortex areas shrank. As suggested by Parazoo et al. (2012), there is net northward transport north of $50^{\circ} \mathrm{N}$. To reveal the transport during the SSWs, we calculated the meridional and vertical residual velocities (Andrews et al. 1987) before and after SSWs. Strong northward meridional residual winds appeared during the SSWs, which could bring midlatitude high concentrations of $\mathrm{CO}_{2}$ into the polar region. As a result, the mean value of the AIRS midtropospheric $\mathrm{CO}_{2}$ concentrations increased after the SSW events (Figs. 4c and 4d). In the vertical direction, the vertical residual velocity results revealed reduced sinking air in the polar region, which is consistent with previous results from Limpasuvan et al. (2004). Less air with the lower $\mathrm{CO}_{2}$ concentration from the upper layer would extend the increase in midtropospheric $\mathrm{CO}_{2}$ concentrations. With both the horizontal and vertical effects, the polar midtropospheric $\mathrm{CO}_{2}$ concentration became higher after the SSW events than before them. In addition to the changes in the horizontal and vertical transports, the change in the $\mathrm{CO}_{2}$ surface emissions might also contribute to the $\mathrm{CO}_{2}$ variations after the SSWs. With a better model in the future, we can diagnose the mechanism on how the SSWs influence the midtropospheric $\mathrm{CO}_{2}$ concentrations.

\section{Conclusions}

We have investigated the influences of the SSWs (final warming in April 2003 and SSW in March 2005) on the AIRS midtropospheric $\mathrm{CO}_{2}$. After the SSW events, the strengths of the polar vortex were weakened. The final warming and SSW had a strong influence on the midtropospheric $\mathrm{CO}_{2}$ concentrations. The polar vortex areas shrank after the SSW, so the midlatitude high concentrations of $\mathrm{CO}_{2}$ were able to propagate to the polar region in the horizontal direction. After the SSW, the strength of the polar vortex was weakened, which was associated with reduced mixing between the stratosphere and troposphere. As a result, the midtropospheric $\mathrm{CO}_{2}$ would have less contamination from the stratospheric low concentrations of $\mathrm{CO}_{2}$. The midtropospheric $\mathrm{CO}_{2}$ concentrations would also increase after the SSW, taking into account the effect in the vertical direction. Utilizing the AIRS midtropospheric $\mathrm{CO}_{2}$, it was found that the mean value of $\mathrm{CO}_{2}$ concentrations in the polar region increased by $2-3$ ppm within a few days after the SSW events. This result is very important for a better understanding of the influence of large-scale dynamics on $\mathrm{CO}_{2}$ in the polar region. It can also be used to track if the SSW signal in the stratosphere can propagate to the troposphere. It is still a challenge to simulate the influence of stratospheric warming on tracers using the current chemistry transport models. The AIRS midtropospheric $\mathrm{CO}_{2}$ can be used to better constrain the stratosphere-troposphere exchange in the models in the future.

Acknowledgments. We thank M. Chahine, Q. Li, two anonymous reviewers, and the editor for helpful comments. X. Jiang was supported by JPL Grant G99694. YLY was supported by the OCO-2 project. Part of the research was carried out at the Jet Propulsion Laboratory, California Institute of Technology, under a contract with the National Aeronautics and Space Administration.

\section{REFERENCES}

Andrews, D. G., J. R. Holton, and C. B. Leovy, 1987: Middle Atmosphere Dynamics. Academic Press, 489 pp.

Aumann, H. H., and Coauthors, 2003: AIRS/AMSU/HSB on the Aqua mission: Design, science objectives, data products, and processing systems. IEEE Trans. Geosci. Remote Sens., 41, 253-264.

—, D. Gregorich, S. Gaiser, and M. Chahine, 2004: Application of atmospheric infrared sounder data (AIRS) to climate research. Sensors, Systems, and Next-Generation Satellites VIII, R. Meynart, S. P. Neeck, and H. Shimoda, Eds., International Society for Optical Engineering (SPIE Proceedings, Vol. 5570), 202-208.

—, S. Broberg, D. Elliott, S. Gaiser, and D. Gregorich, 2006: Three years of Atmospheric Infrared Sounder radiometric calibration validation using sea surface temperatures. J. Geophys. Res., 111, D16S90, doi:10.1029/2005JD006822.

Bacastow, R. B., 1976: Modulation of atmospheric carbon dioxide by the Southern Oscillation. Nature, 261, 116-118.

, C. D. Keeling, and T. P. Whorf, 1985: Seasonal amplitude increase in atmospheric $\mathrm{CO}_{2}$ concentration at Mauna Loa, Hawaii, 1959-1982. J. Geophys. Res., 90 (D6), 10 529-10 540.

Baldwin, M. P., and T. J. Dunkerton, 2001: Stratospheric harbingers of anomalous weather regimes. Science, 294, 581-584.

Chahine, M., C. Barnet, E. T. Olsen, L. Chen, and E. Maddy, 2005: On the determination of atmospheric minor gases by the method of vanishing partial derivatives with application to $\mathrm{CO}_{2}$. Geophys. Res. Lett., 32, L22803, doi:10.1029/2005GL024165.

-, and Coauthors, 2006: AIRS improving weather forecasting and providing new data on greenhouse gases. Bull. Amer. Meteor. Soc., 87, 911-926.

— tropospheric $\mathrm{CO}_{2}$. Geophys. Res. Lett., 35, L17807, doi:10.1029/ 2008GL035022.

Charlton, A. J., and L. M. Polvani, 2007: A new look at stratospheric sudden warmings. Part I: Climatology and modeling benchmarks. J. Climate, 20, 449-469. 
—-, and Coauthors, 2007: A new look at stratospheric sudden warmings. Part II: Evaluation of numerical model simulations. J. Climate, 20, 470-488.

Cleveland, M. S., A. E. Freeny, and T. E. Graedel, 1983: The seasonal component of atmospheric $\mathrm{CO}_{2}$ : Information from new approaches to the decomposition of seasonal time series. J. Geophys. Res., 88 (C15), 10934-10946.

Dargaville, R. J., R. M. Law, and F. Pribac, 2000: Implications of interannual variability in atmospheric circulation on modeled $\mathrm{CO}_{2}$ concentrations and source estimates. Global Biogeochem. Cycles, 14, 931-943.

Dettinger, M. D., and M. Ghil, 1998: Seasonal and interannual variations of atmospheric $\mathrm{CO}_{2}$ and climate. Tellus, 50B, $1-24$.

De Wachter, E., K. Hocke, T. Flury, D. Scheiben, N. Kampfer, S. Ka, and J. J. Oh, 2011: Signatures of the sudden stratospheric warming events of January-February 2008 in Seoul, S. Korea. Adv. Space Res., 48, 1631-1637.

Enting, I. G., 1987: The interannual variation in the seasonal cycle of carbon dioxide concentration at Mauna Loa. J. Geophys. Res., 92 (D5), 5497-5504.

Feely, R. A., R. H. Gammon, B. A. Taft, P. E. Pullen, L. S. Waterman, T. J. Conway, J. F. Gendron, and D. P. Wisegarver, 1987: Distribution of chemical tracers in the eastern equatorial Pacific during and after the 1982-1983 El Niño/Southern Oscillation event. J. Geophys. Res., 92 (C6), 6545-6558.

Garfinkel, C. I., S. B. Feldstein, D. W. Waugh, C. Yoo, and S. Lee, 2012: Observed connection between stratospheric sudden warmings and the Madden-Julian Oscillation. Geophys. Res. Lett., 39, L18807, doi:10.1029/2012GL053144.

Jiang, X., S. Pawson, C. D. Camp, E. Nielsen, R. Shia, T. Liao, V. Limpasuvan, and Y. L. Yung, 2008a: Interannual variability and trends in extratropical ozone. Part I: Northern Hemisphere. J. Atmos. Sci., 65, 3013-3029.

,,,,,----- , and,$- 2008 \mathrm{~b}$ : Interannual variability and trends in extratropical ozone. Part II: Southern Hemisphere. J. Atmos. Sci., 65, 3030-3041.

—, M. T. Chahine, E. T. Olsen, L. L. Chen, and Y. L. Yung, 2010: Interannual variability of mid-tropospheric $\mathrm{CO}_{2}$ from Atmospheric Infrared Sounder. Geophys. Res. Lett., 37, L13801, doi:10.1029/2010GL042823.

$\longrightarrow,-$, Q. Li, M. Liang, E. T. Olsen, L. L. Chen, J. Wang, and Y. L. Yung, 2012: $\mathrm{CO}_{2}$ semiannual oscillation in the middle troposphere and at the surface. Global Biogeochem. Cycles, 26, GB3006, doi:10.1029/2011GB004118.

— Licata, and Y. L. Yung, 2013: Influence of El Niño on midtropospheric $\mathrm{CO}_{2}$ from Atmospheric Infrared Sounder and model. J. Atmos. Sci., 70, 223-230.

Jones, C. D., M. Collins, P. M. Cox, and S. A. Spall, 2001: The carbon cycle response to ENSO: A coupled climate-carbon cycle model study. J. Climate, 14, 4113-4129.

Keeling, C. D., and R. Revelle, 1985: Effects of ENSO on the atmospheric content of carbon dioxide. Meteroritics, 20, 437-450.

_, T. P. Whorf, M. Wahlen, and J. Vanderplicht, 1995: Interannual extremes in the rate of rise of atmospheric carbon dioxide since 1980. Nature, 375, 666-670.

— J. F. S. Chin, and T. P. Whorf, 1996: Increased activity of northern vegetation inferred from atmospheric $\mathrm{CO}_{2}$ measurements. Nature, 382, 146-149.

Keppel-Aleks, G., P. O. Wennberg, and T. Schneider, 2011: Sources of variations in total column carbon dioxide. Atmos. Chem. Phys., 11, 3581-3593.
Kodera, K., Y. Kuroda, and S. Pawson, 2000: Stratospheric sudden warmings and slowly propagating zonal-mean wind anomalies. J. Geophys. Res., 105 (D10), 12351-12359.

Kuttippurath, J., and G. Nikulin, 2012: A comparative study of the major sudden stratospheric warmings in the Arctic winters 2003/2004-2009/2010. Atmos. Chem. Phys., 12, 81158129.

Labitzke, K., 1977: Interannual variability of the winter stratosphere in the Northern Hemisphere. Mon. Wea. Rev., 105, 762-770.

—, and B. Naujokat, 2000: The lower arctic stratosphere in winter since 1952. SPARC Newsletter, No. 15, SPARC International Project Office, Zurich, Switzerland, 11-14.

Li, K.-F., B. Tian, D. E. Waliser, and Y. L. Yung, 2010: Tropical midtropospheric $\mathrm{CO}_{2}$ variability driven by the Madden-Julian oscillation. Proc. Natl. Acad. Sci. USA, 107, 19171-19175.

Limpasuvan, V., D. W. J. Thompson, and D. L. Hartmann, 2004: The life cycle of the Northern Hemisphere sudden stratospheric warmings. J. Climate, 17, 2584-2596.

Manney, G. L., K. Kruger, J. L. Sabutis, S. A. Sena, and S. Pawson, 2005: The remarkable 2003-2004 winter and other recent warm winters in the Arctic stratosphere since the late 1990s. J. Geophys. Res., 110, D04107, doi:10.1029/2004JD005367.

_ vations of dynamics and transport during the record-breaking 2009 Arctic stratospheric major warming. Geophys. Res. Lett., 36, L12815, doi:10.1029/2009GL038586.

Nevison, C. D., and Coauthors, 2008: Contribution of ocean, fossil fuel, land biosphere, and biomass burning carbon fluxes to seasonal and interannual variability in atmospheric $\mathrm{CO}_{2}$. J. Geophys. Res., 113, G01010, doi:10.1029/2007JG000408.

Olsen, E. T., 2011: Reaching for the middle troposphere and lower troposphere for AIRS $\mathrm{CO}_{2}$ retrievals-Progress toward the retrieval of a profile. Proc. AIRS Science Team Meeting, Pasadena, CA, NASA Jet Propulsion Laboratory.

, M. T. Chahine, L. Chen, X. Jiang, T. S. Pagano, and Y. L. Yung, 2008: Validation of AIRS Retrievals of $\mathrm{CO}_{2}$ via comparison to in-situ measurements. Eos, Trans. Amer. Geophys. Union, 89 (Fall Meeting Suppl.), Abstract A32B-04.

— X. Jiang, L. Chen, S. Licata, T. Pagano, and Y. Yung, 2011: Application of AIRS stratospheric $\mathrm{CO}_{2}$ to investigate stratospheric transport and troposphere-stratosphere exchange. 2011 Fall Meeting, San Francisco, CA, Amer. Geophys. Union, Abstract A33C-0219.

Parazoo, N. C., A. S. Denning, S. R. Kawa, S. Pawson, and R. Lokupitiya, 2012: $\mathrm{CO}_{2}$ flux estimation errors associated with moist atmospheric processes. Atmos. Chem. Phys., 12, 64056416.

Pearman, G. I., and P. Hyson, 1980: Activities of the global biosphere as reflected in atmospheric $\mathrm{CO}_{2}$ records. J. Geophys. Res., 85 (C8), 4457-4467.

- and -1981 : The annual variation of atmospheric $\mathrm{CO}_{2}$ concentration observed in the northern hemisphere. J. Geophys. Res., 86 (C10), 9839-9843.

Preisendorfer, R. W., 1988: Principal Component Analysis in Meteorology and Oceanography. Elsevier Science, $425 \mathrm{pp}$.

Quiroz, R. S., 1975: The stratospheric evolution of sudden warmings in 1969-74 determined from measured infrared radiation fields. J. Atmos. Sci., 32, 213-224.

_ _ A. J. Miller, and R. M. Nagatani, 1975: Comparison of observed and simulated properties of sudden stratospheric warmings. J. Atmos. Sci., 32, 1723-1736.

Richman, M. B., 1986: Rotation of principal components. J. Climatol., 6, 293-335. 
Sofieva, V. F., N. Kalakoski, P. T. Verronen, S. M. Paivarinta, E. Kyrola, L. Backman, and J. Tamminen, 2012: Polar-night $\mathrm{O}_{3}, \mathrm{NO}_{2}$ and $\mathrm{NO}_{3}$ distributions during sudden stratospheric warmings in 2003-2008 as seen by GOMOS/Envisat. Atmos. Chem. Phys., 12, 1051-1066.

Susskind, J., C. Barnet, and J. Blaisdell, 2003: Retrieval of atmospheric and surface parameters from AIRS/AMSU/HSB data in the presence of clouds. IEEE Trans. Geosci. Remote Sens. 41, 390-409.
Thompson, D. W. J., and J. M. Wallace, 2000: Annular modes in the extratropical circulation. Part I: Month-to-month variability. J. Climate, 13, 1000-1016.

Wang, J., and Coauthors, 2011: The influence of tropospheric biennial oscillation on mid-tropospheric $\mathrm{CO}_{2}$. Geophys. Res. Lett., 38, L20805, doi:10.1029/2011GL049288.

Yoshida, K., and K. Yamazaki, 2011: Tropical cooling in the case of stratospheric sudden warming in January 2009: Focus on the tropical tropopause layer. Atmos. Chem. Phys., 11, 6325-6336. 